\title{
In vivo assessment of anticoagulant and antiplatelet effects of Syzygium cumini leaves extract in rabbits
}

\author{
Ahad Abdul Rehman', Azra Riaz², Muhammad Arif Asghar ${ }^{3 *} \mathbb{D}$, Muhammad Liaquat Raza $^{4}$, Shadab Ahmed ${ }^{2}$ and \\ Kamran Khan ${ }^{3}$
}

\begin{abstract}
Background: Syzygium cumini (L.) Skeels. is one of the very popular traditionally used medicinal plants with numerous pharmacological activities including antioxidant, hypoglycemic and anti-inflammatory. However, actions of S. cumini on blood coagulation and other parameters of blood were poorly pharmacologically studied. Therefore, aim of this present investigation is to examine the effects of methanolic extract of $S$. cumini on blood coagulation and anticoagulation factors in healthy white albino rabbits at different doses.
\end{abstract}

Methods: Blood samples were drawn twice during this study and biochemical assays were performed to determine the effect on different parameters such as coagulation, anticoagulation, hematological, Protein C (PC) and thrombin antithrombin (TAT) complex and platelet aggregation.

Results: The results showed significant increase in RBCs, hemoglobin, hematocrit and platelets counts up to $1.4 \times 10^{3} / \mathrm{cm}, 2.2 \mathrm{~g} / \mathrm{dl}, 6 \%, 248.2 \times 10^{3} / \mathrm{cm}$ respectively. While, thrombin and bleeding time were also prolonged in dose dependent manner which is highly significant $(p \leq 0.005)$ as compared to control. Similarly, highly significantly increased $(p \leq 0.005)$ in levels of protein $C$, thrombin antithrombin complex at dose of 500 $\mathrm{mg} / \mathrm{kg}$ were observed. Whereas, levels of platelets aggregation and fibrinogen were decreased at high doses.

Conclusion: The obtained findings of hematological and coagulation tests concludes possibly S. cumini possess anticoagulant and antiplatelet effects.

Keywords: Syzygium cumini, Coagulation, Platelets, Thrombin, Prothrombin

\section{Background}

Human beings are using plants as medicine since centuries. Biological activities present in these plants and their derivatives are of great importance in healthcare history. Studies suggested that $30 \%$ of the all recent drugs are derived products of different plant species [1]. According to a survey conducted by World Health Organization (WHO), 80\% of human population is largely dependent on plant sources for treatment of minor ailments. Recently, demand and importance of medicinal plants is increasing day by day due to its wide acceptance worldwide [2].

\footnotetext{
* Correspondence: m.arifasgher@hotmail.com

${ }^{3}$ Department of Pharmaceutics, Faculty of Pharmacy, Jinnah Sindh Medical

University, Rafiqui H.J Shaheed Road, Karachi 75510, Pakistan

Full list of author information is available at the end of the article
}

Plants and their derived products provides vital source, on which healthcare system of prehistoric population largely depends. Now a day, demand of new chemical moiety for the improvement of healthcare system is greatly supported by plant resources [3]. Studies showed that complementary and alternative medicine (CAM) also contributes their significant part in the treatment of cardiovascular related health problems, while herbal products are the most frequent part of CAM treatment [4].

Hemostasis is a normal physiological phenomenon in our internal body's defense system that prevents loss of blood after hemorrhage, which converts blood into thick jell like mass at point of injury/damage. Blood coagulation is one of the steps in hemostasis mechanism which is responsible for the formation of blood clot that

(c) The Author(s). 2019 Open Access This article is distributed under the terms of the Creative Commons Attribution 4.0 International License (http://creativecommons.org/licenses/by/4.0/), which permits unrestricted use, distribution, and reproduction in any medium, provided you give appropriate credit to the original author(s) and the source, provide a link to the Creative Commons license, and indicate if changes were made. The Creative Commons Public Domain Dedication waiver (http://creativecommons.org/publicdomain/zero/1.0/) applies to the data made available in this article, unless otherwise stated. 
restricts flow of blood at site of injury. The mechanism of coagulation is a multi-step process involving activation of various enzymes which ultimately use its specific substrate and converts it into active enzyme [5]. Such proteolytic cascade proceeds till the formation of thrombin. Newly formed thrombin then breaks down soluble fibrinogen into insoluble fibrin which results in the formation of blood clot. Any inappropriateness in coagulation cascade may lead to pathological conditions i.e. venous thrombosis [6]. Atherosclerosis and several cardiovascular diseases can also be prevented by reducing thrombus formation and inhibition of coagulation cascade [7].

Syzygium cumini belongs to Myrtaceae family. It is widely distributed throughout the South Asian continent including Pakistan, India, Indonesia and Sri-Lanka. Chemically, leaves of S. cumini mainly contain high percentage of flavonoids i.e. ferulic acid, rutin and catechin while limonene found as major constituent of its essential oil [8].

Traditionally, S. cumini is reported in the treatment of ulcers, biliousness, bronchitis, dysentery, diabetes and its related complications. Moreover, leaf extract of S. cumini showed antimicrobial, anti-inflammatory, antinociceptive, antioxidant, antihyperlipidemic and cardioprotective potentials [9-13]. Cardioprotective potential of $S$. cumini in oxidative stress induced cardiac myocytes and protective effect in isoproterenol-induced myocardial infarction has also been reported [14]. Myricetin, catechin, and rutin present are common flavonoid found in the methanolic leaf extract of S. cumini possess a potent antioxidant activity [15]. Moreover, Mohamed et al. also reported $\alpha$-pinene, camphene, myrcene, $\beta$-pinene and limonene are also responsible for antioxidant activity [16]. These polyphenolic compounds are effective due to free radical scavenging property along with their effects on cell signaling cascades and gene expression which would be helpful in increased synthesis of cells that leads to improve the blood cells count [17]. Different animal models have been used in thrombosis and atherosclerosis research studies, but no model completely mimics the disorders found in humans. Moreover, to our knowledge, only in vitro studies are conducted related to the development of atherosclerosis with one was having same methodology on Punica granatum [18]. Large animal models with more blood volume have, however, demonstrated a better suitability for translation to humans. Hence, rabbits were used in the current study because direct transformation from mice to humans may result in species-related differences. There is no previous report on anticoagulation and antiplatelet activities of S. cumini in literature to the best of our knowledge. Therefore the present study was conducted to evaluate the activity of S. cumini extract on blood coagulation and different blood parameters using rabbit's model.

\section{Materials and methods Animals}

This study was conducted on sixty healthy white male albino rabbits which were purchased from animal house of Dow University of Health Sciences, (DUHS), Karachi with average body weight of $1250 \pm 50 \mathrm{~g}$. Rabbits were chosen due to larger volume of blood was required to perform blood coagulation test and other parameters of study Animals were kept under prerequisite temperature of $23^{\circ} \mathrm{C} \pm 2{ }^{\circ} \mathrm{C}$ with humidity $50-60 \%$ in a light-dark cycle of $12 \mathrm{~h}$ each. Both control and tested animals were kept in same environment and provided with the standard food. Steel bottom cages were used to keep each rabbit separately with free access of food and water.

\section{Ethics and consent}

Use of rabbits in this study was in accordance with the National Advisory Committee for Laboratory Animal Research guide for the care and use of Laboratory Animals and under the acquiescence of the Board of Advance Studies and Research, University of Karachi, Pakistan. The written consent form was also filled by the in-charge of the animal house (DUHS) to use these animals for our study. The study was approved by local research ethics committee of Board of Advance Studies and Research, University of Karachi, Pakistan and also approved by research review committee of Ziauddin Hospital Karachi-Pakistan with the reference number of 27/02/KK/ZHC.

\section{Plant material and extraction}

Fresh leaves of Syzygium cumini (L.) Skeels. were purchased in the month of July from local commercial herbal research market of Lyari town, Karachi, Pakistan. It was identified by the meritorious Professor and Pharmacognosist Prof. Dr. Mansoor Ahmed at Center of Plant Conversation, University of Karachi, Pakistan with G.H. No. 94236. Leaves were washed using fresh water and allowed to air dry at room temperature. Then, grind by electrical blender. Approximately $200 \mathrm{~g}$ of powdered material was soaked in $500 \mathrm{~mL}$ of methanol (HPLC grade) for 2 weeks in a static condition. Separation of plant material from methanol was done through filtration using Whatman no. 1 filter paper, and then filtrate was concentrated using a rotary evaporator (IKA, Germany) at $40^{\circ} \mathrm{C}$ under reduced pressure [19]. The final product was a dark brownish sticky mass weighing $7.3 \mathrm{~g}$, which represents a yield of $3.65 \%$.

\section{Drug treatment}

Animals were divided into five groups with 10 rabbits in each group. 1st group received distilled water and served as control group for 2 months; 2nd and 3rd groups were administered orally with $S$. cumini leaves extract using 
two different doses i.e. $150 \mathrm{mg} / \mathrm{kg}$ and $500 \mathrm{mg} / \mathrm{kg}$ once daily. Whereas, 4th and 5th groups, served as standard drug's group and received aspirin and warfarin respectively. Duration for warfarin administration was 6 days i.e. 3 days, initial dose used was $5 \mathrm{mg} / \mathrm{kg}$, however, during later 3 days, $10 \mathrm{mg} / \mathrm{kg}$ dose was given. Aspirin was given at the dose of $150 \mathrm{mg} / \mathrm{kg}$, once in a day for 6 days/ week. Blood samples were drawn prior to $6 \mathrm{~h}$ fasting (avoid lipemia) at day 30th and 60th respectively, in ethylene diamine tetra acetate (EDTA) and trisodium citrate containing tubes and gel tubes from most dominant ear vein of rabbit [18]. Rabbits were humanely euthanatized by administration of Beuthanasia solution $(100 \mathrm{mg} / \mathrm{ml}$ perntabarbitol, $1 \mathrm{ml} / 10 \mathrm{lbs})$ intravenously in the ear. Prior to euthanasia, each rabbit was sedated with an intramuscular injection of medetomidine $(0.5 \mathrm{mg} / \mathrm{kg})$ and ketamine $(10 \mathrm{mg} / \mathrm{kg})$.

\section{Hematological parameters}

Following blood parameters were studied using hematology analyzer (Beckman Coulter, Inc. U.S). RBCs (Red blood cells), WBCs (White blood cells), platelets count, $\mathrm{Hb}$ (Hemoglobin concentration), MCH (Mean corpuscular hemoglobin), HCT (Hematocrit), MCV (Mean corpuscular volume), MCHC (Mean corpuscular hemoglobin concentration) and red cell distribution width.

\section{Bleeding time estimation}

Bleeding time in studied animals was estimated according to the modified method [20]. Briefly, a minor incision (5 $\mathrm{mm}$ long and $1 \mathrm{~mm}$ deep) was made in the central artery of ear after removal of hairs. The slit opening was dried using blotting paper after every $30 \mathrm{~s}$ till the bleeding was stopped.

\section{Estimation of fibrinogen levels, thrombin, prothrombin and activated partial thromboplastin time}

Trisodium citrate tubes were used to separate plasma from blood samples by centrifugation at $2000 \times g$ for 10 min. Humaclot duo coagulometer and human reagent kits (Huma count, Germany) were used to perform these tests. Clot formation was evaluated by turbidimetric technique, and changed in optimal plasma density was used to determine coagulation endpoint. Thrombin reagent $(100 \mu \mathrm{L})$ was mixed with $200 \mu \mathrm{L}$ plasma for determination of thrombin time (TT). While, prothrombin time (PT) was determined by adding $200 \mu \mathrm{L}$ of thromboplastin reagent in $100 \mu \mathrm{L}$ of plasma. The mixture was then incubated with aPTT-EL reagent $(100 \mu \mathrm{L})$ at $37^{\circ} \mathrm{C}$ for $15 \mathrm{~min}$, further $\mathrm{CaCl}_{2}$ was added to determine activated partial thromboplastin time (aPTT). The level of fibrinogen was estimated using the method as described by McNerlan et at. [21].

\section{Platelets aggregation test}

To assess platelet function, Agg RAM aggregometer (Helena Biosciences, Europe) was used, manufacturer instructions were followed. Blood was taken in the ratio of $9: 1 \mathrm{v} / \mathrm{v}$ in trisodium citrate (3.8\%). This analysis is necessary the use of platelets poor plasma (PPP). Therefore, blood samples were centrifuged for $14 \mathrm{~min}$ at $100 \times \mathrm{g}$ and residual blood for $15 \mathrm{~min}$ at $1800 \times g$ in $14 \mathrm{~K}$ Humax to form platelets rich plasma (PRP) and PPP respectively. PRP prepared samples were standardized (approx. 250, $000 / \mathrm{mm}^{3}$ ) with autologous PPP as needed [22]. Reactivity of platelets was evaluated at $37^{\circ} \mathrm{C}$ for $10 \mathrm{~min}$ adopting method of Jeong et al. [23]. PRP absorbance denotes $0 \%$ aggregation and PPP absorbance denotes as 100\% aggregation. Platelet aggregation was induced by arachidonic acid (AA), adenosine diphosphate (ADP), collagen and epinephrine. PRP $(450 \mu \mathrm{L})$ was taken into cuvettes for incubation, while, PPP cuvette set to $100 \%$ aggregation using aggregating reagent. Transmittance was used for the determination of resultant aggregation and was expressed as \%.

\section{Protein C (PC) and thrombin antithrombin (TAT) complex} PC and TAT complex kits of Elisa (Biotech Ltd. India) were used to determine the activity of protein $C$ and thrombin-antithrombin complex. Absorbance of standard plasma was used as standard curves for PC and TAT complexes at $450 \mathrm{~nm}$. However, activity of PC and TAT complexes in samples were referred as standard plasma activity. The guidelines of National Committee for Clinical Laboratory were followed for all estimations [24].

\section{Phytochemical characterization}

Different standard chemical methods were utilized to determine the chemical composition in S. cumini methanolic leaves extract. Phytochemicals including flavonoids, phenolic compounds, terpenoids, tannins and alkaloids were screened using different identification tests i.e. Shinoda test, Ellagic Acid Test, Salkowski test, Ferric Chloride Test and Mayer's test respectively [25].

\section{Statistical analysis}

Data was represented as mean with standard error (SEM) and was analyzed using SPSS version 23 (IBM, USA). ANOVA with post-hoc analysis was utilized for values comparisons with control. $P$-values at level of $<$ $0.05 \& P<0.005$ were considered as significant and highly significant respectively.

\section{Results}

Overall animal's health evaluation such as average weight variation, skin ulceration, loss of activity, diarrhea, hematuria, salivation, tremor, vomiting, edema and 
aggressive behavior were observed in all control and test groups before and during the total period of experiment.

Table 1 reveals the effect of $S$. cumini on bleeding time (BT), Thrombin time (TT), Prothrombin time (PT), activated partial thromboplastin time (aPTT) and Fibrinogen $(\mathrm{Fb})$ levels. At day 30th and 60th, there was highly significant increase in BT, while, decrease in Fb levels at both doses of S. cumini respectively. Significant increase in aPTT was observed by SCD1 and SCD2, whereas, PT was increased at 60th day in SCD2 group. Changes in TT were not significant after 30 and 60 days at both the doses as compared to the control group.

Table 2 displays the effect of S. cumini extract on hematological parameters. High doses of extract showed significant increase in $\mathrm{Hb}$ and $\mathrm{RBC}$ count at day 30th when compared with control group, whereas, significant and highly significant increase was observed at 30th and 60 th day respectively. However, $\mathrm{HCT}, \mathrm{MCV}, \mathrm{MCH}$, $\mathrm{MCHC}$ and WBC counts were not altered significantly at any dose of S. cumini. Highly significant increase was found in platelets count at both doses after 30th. While, highly significant and significant increase was observed by SCD1 and SCD2 at 60th day respectively.

Table 3 shows the activity of S. cumini on inhibition of platelet aggregation at two different concentrations. The methanolic extract of S. cumini significantly inhibited ADP and epinephrine induced platelets aggregation at $150 \mathrm{mg} / \mathrm{kg}$ concentration for 30 and 60 days. At $500 \mathrm{mg} /$ $\mathrm{kg}$, extract showed significant inhibition of platelets induced by AA, ADP, collagen and epinephrine in a group that received extract for 60 days. While inhibition after 30 days, was associated with only collagen and epinephrine. Moreover, Table 4 shows the presence of different phytochemical constituents such as flavonoids, phenolic constituents, terpenoids, tannins and alkaloids in methanolic leaves extract of $S$. cumini using different chemical identification tests.
Figures 1 and 2 shows the effect of S. cumini on PC and plasma activity of TAT complexes. In Fig. 1, animals received SCD2 showed significant increase in $\mathrm{PC}$ level at 60th day as compare to control group. Moreover at SCD2, S. cumini also showed significant increase in TAT complex activity at 30th and 60th day presented in Fig. 2.

\section{Discussion}

Danger of bleeding could be explained by BT and various coagulation tests i.e. TT, PT, aPTT and Fb levels [26]. Therefore, these tests were used to evaluate effect of S. cumini extract on coagulation and its potential for related cardiovascular problems.

PT and aPTT are important evaluation tests used to determine intrinsic and extrinsic pathways of coagulation [27]. It was observed in this study that aPTT at 30th and 60th day were significantly increase. It is reported that inhibition of intrinsic coagulation factors is responsible for aPTT prolongation $[5,18]$. This response could be linked with the hyperlipidemic effect of $S$. cumini [28]. Significant increase in clotting factors II, VII, and X was reported due to high cholesterol diet in rabbits [29]. Increase in plasma concentration of clotting factors stimulates in response to greater catabolic rate of prothrombin [30]. Hence, we may associate that cholesterol lowering potential of $S$. cumini could be the reason of prolongation in aPTT.

SCD2 prolongs aPTT, which shows that there is inhibition of intrinsic pathway of coagulation process. It is evident that S. cumini contains limonene, flavonoids and phenolic acids that may prolong aPTT [30]. Results of the study showed that there is highly significant reduction in fibrinogen concentration at 30th and 60th day and these reduced levels leads to increase in bleeding time. Hence, it may be concluded that inhibition of platelet aggregation might be due to this effect of $S$.

Table 1 In vivo comparison of Syzygium cumini leaves extract, warfarin and control on rabbit's coagulation parameters. Humaclot duo coagulometer and human reagent kits were used to perform these tests. Clot formation was evaluated by turbidimetric technique

\begin{tabular}{|c|c|c|c|c|c|c|}
\hline \multirow[t]{2}{*}{ Groups } & \multirow[t]{2}{*}{ Days } & \multicolumn{5}{|l|}{ Parameters } \\
\hline & & $\mathrm{BT}(\mathrm{Sec})$ & $\Pi$ T (Sec) & PT (Sec) & aPTT (Sec) & $\mathrm{Fb}(\mathrm{mg} / \mathrm{dl})$ \\
\hline \multirow[t]{2}{*}{ Control } & 30 & $180.8 \pm 36.82$ & $20.6 \pm 3.36$ & $12.7 \pm 0.85$ & $14.6 \pm 1.57$ & $401.6 \pm 24.66$ \\
\hline & 60 & $170.8 \pm 19.38$ & $21.2 \pm 2.77$ & $12.3 \pm 1.05$ & $14.2 \pm 0.92$ & $410.6 \pm 17.79$ \\
\hline \multirow[t]{2}{*}{ SCD1 } & 30 & $337.2 \pm 11.69^{* *}$ & $22.6 \pm 2.61$ & $17.4 \pm 3.32$ & $19.1 \pm 1.69^{*}$ & $331.6 \pm 13.72^{* *}$ \\
\hline & 60 & $341.2 \pm 7.39^{* *}$ & $23.0 \pm 2.00$ & $14.22 \pm 1.54$ & $17.9 \pm 2.10^{*}$ & $320.2 \pm 29.12^{* *}$ \\
\hline \multirow[t]{2}{*}{ SCD2 } & 30 & $315.0 \pm 66.33^{* *}$ & $26.8 \pm 1.92$ & $24.4 \pm 2.30$ & $19.3 \pm 3.45^{*}$ & $316.0 \pm 23.45^{* *}$ \\
\hline & 60 & $303.0 \pm 44.38^{* *}$ & $24.8 \pm 2.73$ & $17.2 \pm 2.19^{* *}$ & $17.6 \pm 2.07^{*}$ & $326.6 \pm 26.26^{* *}$ \\
\hline Warfarin & - & $335.4 \pm 24.60^{* *}$ & $31.8 \pm 4.97^{* *}$ & $64.4 \pm 17.21^{* *}$ & $30.1 \pm 1.30^{* *}$ & $303.0 \pm 21.54^{* *}$ \\
\hline
\end{tabular}

$n=10$, Average values \pm SEM,

${ }^{*} p \leq 0.05$ significant as compared to control, ${ }^{* *} p \leq 0.005$ highly significant as compared to control

SCD1: S. cumini dose 1; i.e. $150 \mathrm{mg} / \mathrm{kg}$, SCD2: S. cumini dose 2; i.e. $500 \mathrm{mg} / \mathrm{kg}$

$B T$ Bleeding time, $T$ Thrombin time, $P T$ Prothrombin time, $A P T T$ activated partial thromboplastin time, Fb Fibrinogen level 
Table 2 In vivo effects of Syzygium cumini leaves extract and control on rabbit's hematological parameters

\begin{tabular}{llllllllll}
\hline Groups & Days & Parameters & \multicolumn{1}{l}{$l$} & & & \\
\cline { 3 - 9 } & & $\mathrm{Hb}(\mathrm{g} / \mathrm{dl})$ & $\mathrm{RBC}\left(\times 10^{3} / \mathrm{mm}^{3}\right)$ & $\mathrm{HCT}(\%)$ & $\mathrm{MCV}(\%)$ & $\mathrm{MCH}(\mathrm{pg} / \mathrm{cell})$ & $\mathrm{MCHC}(\%)$ & $\mathrm{WBC}\left(\times 10^{3} / \mathrm{mm}^{3}\right)$ & Platelets $\left(\times 10^{3} / \mathrm{mm}^{3}\right)$ \\
\hline Control & 30 & $9.4 \pm 1.46$ & $4.6 \pm 0.67$ & $30.8 \pm 4.55$ & $67.2 \pm 2.77$ & $21.4 \pm 2.19$ & $30.2 \pm 1.64$ & $4.8 \pm 1.13$ & $284.4 \pm 64.19$ \\
& 60 & $9.5 \pm 1.29$ & $4.5 \pm 0.63$ & $29.8 \pm 4.76$ & $68.2 \pm 2.68$ & $20.8 \pm 1.64$ & $29.4 \pm 1.52$ & $4.9 \pm 1.17$ & $296.2 \pm 59.46$ \\
SCD1 & 30 & $10.4 \pm 1.04$ & $4.9 \pm 0.41$ & $32.2 \pm 1.92$ & $68.2 \pm 3.35$ & $21.2 \pm 1.10$ & $30.4 \pm 1.52$ & $4.2 \pm 0.45$ & $532.6 \pm 60.84^{* *}$ \\
& 60 & $10.6 \pm 0.72$ & $5.0 \pm 0.17$ & $31.2 \pm 2.59$ & $67.0 \pm 3.16$ & $20.6 \pm 1.14$ & $31.0 \pm 1.41$ & $4.1 \pm 0.43$ & $519.0 \pm 46.56^{* *}$ \\
SCD2 & 30 & $11.5 \pm 0.49^{*}$ & $5.8 \pm 0.51^{*}$ & $35.2 \pm 1.92$ & $66.6 \pm 3.65$ & $20.6 \pm 1.82$ & $30.6 \pm 1.14$ & $4.7 \pm 1.31$ & $449.4 \pm 54.17^{* *}$ \\
& 60 & $11.6 \pm 0.37^{*}$ & $5.9 \pm 0.47^{* *}$ & $35.8 \pm 2.59$ & $67.4 \pm 2.30$ & $21.2 \pm 1.10$ & $31.2 \pm 0.84$ & $4.6 \pm 1.31$ & $459.4 \pm 53.15^{*}$ \\
\hline
\end{tabular}

$n=10$, Average values \pm SEM;

SCD1: S. cumini dose $1 ; 150 \mathrm{mg} / \mathrm{kg} ;$ SCD2: S. cumini dose $2 ; 500 \mathrm{mg} / \mathrm{kg}$

${ }^{*} p \leq 0.05$ significant as compared to control; ${ }^{* *} p \leq 0.005$ highly significant as compared to control

Hb Hemoglobin, RBC Red blood cells, HCT Hematocrit, MCV Mean corpuscular volume, MCH Mean corpuscular hemoglobin, MCHC Mean corpuscular hemoglobin concentration, WBC White blood cells

cumini, since platelets need fibrinogen to activate aggregation of platelets [31]. Due to this, inhibition of platelet aggregation increases the bleeding time. Moreover, this observed activity might be due to the presence of quercetin responsible for inhibition of platelets functions by acting on phospholipase $\mathrm{C}$ pathway. Presence of anthocyanins in S. cumini might be also responsible for inhibition of platelet aggregation [9].

Various other studies reported that PC and TAT complexes were presented as biomarker for cardiovascular and thrombotic events [30]. As S. cumini increased the levels of these biomarker which in turn is cause of reduce thrombin activity. This effect is similar to that of known anticoagulant drug, heparin, which might be probable reason for prolonged bleeding time. It is known that heparin potentiates synthesis of anti-thrombin III (AT-III), which ultimately, promotes complex formation with thrombin and deactivates multiple coagulation factors that increase duration of aPTT [18]. AT-III and activated form of PC play major role as natural anticoagulant. AT-III retards activated clotting factors i.e. factor Xa and thrombin (factor IIa). The increase of thrombin inhibition due to incorporation with AT-III can be estimated by TAT complex [32]. PC is also play its role in reducing thrombin and deactivate the factor VIIIa and factor Va by combining with protein S [33].

Evaluation of hematological variables could be utilized to unveil unfavorable effects of exogenous compounds i.e. plant extracts on the composition of blood in animal model [34]. Disturbance in the hematological values reflect variation in normal physiological status which also provide useful information about normal histology and histopathology of organs.

Parameters of red blood cells i.e. Hb, RBC, HCT, MCV, $\mathrm{MCH}$, and $\mathrm{MCHC}$ were performed to evaluate the effects of S. cumini leaves extract in anemic state. Following administration of S. cumini extract, RBC and Hb levels were significantly increased, specifically at $500 \mathrm{mg} / \mathrm{kg}$. It indicates that $S$. cumini plant extract might contain some active chemical moiety which can promote the erythropoietin secretion in stem cells. Erythropoietin is a stimulator hormone for red blood cells formation in the bone

Table 3 In vivo comparison of S. cumini leaves extract, aspirin and control on inhibition of platelet aggregation in rabbits. Agg RAM aggregometer was used to perform this test. Blood was taken in the ratio of 9:1 v/v in trisodium citrate (3.8\%)

\begin{tabular}{|c|c|c|c|c|c|}
\hline \multirow[t]{2}{*}{ Groups } & \multirow[t]{2}{*}{ Days } & \multicolumn{4}{|c|}{ Inhibition of platelet aggregation (\%) } \\
\hline & & $\mathrm{AA}(500 \mu \mathrm{g} / \mathrm{mL})$ & ADP $(20 \mu \mathrm{mol} / \mathrm{L})$ & Collagen $(10 \mu \mathrm{g} / \mathrm{mL})$ & Epinephrine $(300 \mu \mathrm{mol} / \mathrm{L})$ \\
\hline \multirow[t]{2}{*}{ Control } & 30 & $69.54 \pm 8.12$ & $41.54 \pm 3.24$ & $20.74 \pm 1.54$ & $14.65 \pm 0.88$ \\
\hline & 60 & $76.12 \pm 7.58$ & $41.66 \pm 3.68$ & $20.65 \pm 0.89$ & $14.24 \pm 0.97$ \\
\hline \multirow[t]{2}{*}{ SCD1 } & 30 & $65.29 \pm 6.21^{*}$ & $36.66 \pm 0.54^{*}$ & $20.41 \pm 0.75$ & $13.45 \pm 1.24$ \\
\hline & 60 & $57.55 \pm 7.08^{*}$ & $37.80 \pm 0.87^{*}$ & $17.54 \pm 1.12^{*}$ & $13.20 \pm 1.54^{*}$ \\
\hline \multirow[t]{2}{*}{ SCD2 } & 30 & $60.89 \pm 6.29^{* *}$ & $35.37 \pm 0.70^{*}$ & $18.80 \pm 0.98$ & $13.98 \pm 0.95$ \\
\hline & 60 & $52.06 \pm 5.98^{* *}$ & $33.65 \pm 1.21^{*}$ & $16.99 \pm 2.54^{*}$ & $13.00 \pm 0.84^{*}$ \\
\hline \multirow[t]{2}{*}{ Aspirin } & 30 & $43.44 \pm 8.45^{* *}$ & $30.45 \pm 0.98^{* *}$ & $12.87 \pm 1.23^{* *}$ & $12.59 \pm 1.05^{*}$ \\
\hline & 60 & $46.87 \pm 8.99^{* *}$ & $26.76 \pm 1.25^{* *}$ & $12.33 \pm 1.01^{* *}$ & $12.98 \pm 0.90^{*}$ \\
\hline
\end{tabular}

$n=10$, Average values \pm SEM;

SCD1: S. cumini dose $1 ; 150 \mathrm{mg} / \mathrm{kg}$; SCD2: S. cumini dose $2 ; 500 \mathrm{mg} / \mathrm{kg}$

${ }^{*} p \leq 0.05$ significant as compared to control; ${ }^{* *} p \leq 0.005$ highly significant as compared to control

$A A$ Arachidonic acid, ADP Adenosine diphosphate 
Table 4 Presence of phytochemical components in S. cumini methanolic leaves extract

\begin{tabular}{lll}
\hline S. No. & Phytochemicals & Results \\
\hline 1 & Flavonoids & Positive \\
2 & Phenolic compounds & Positive \\
3 & Terpenoids & Positive \\
4 & Tannins & Positive \\
5 & Alkaloids & Positive \\
\hline aresence of phytochemicals &
\end{tabular}

marrow [35]. This increase in RBC count improves the oxygen carrying potential of blood. Although mechanism behind this parameter is not being explored in this study, but it could be due to the phytochemical constituents that are present in this plant extract. These phytochemicals may be responsible for reduction in lipid peroxidation that ultimately prevent RBC's haemolysis and improves its turnover. Previous study about phytochemical constituents of this plant unveiled the presence of polyphenolic compounds and flavonoids which possessed good antioxidant potential [9]. Hence, could retard the lipid peroxidation of cell membrane and haemolysis of RBSs. Platelet also plays vital role in maintenance of hemostasis. Hence low platelet counts or thrombocytopenia leads to hemorrhage or severe loss of blood [36]. Both doses of S. cumini showed significant increase in platelet count. It is reported that this increased platelet effect by S. cumini could be due to antioxidant potential effect of flavonoids present in it [8]. There was, however, significant increase in platelets count by $S$. cumini extract. This could be credited to the antioxidant activity of the flavonoids, quercetin, catechin, myricetin and rutin present which was found in methanolic leaves extract $[8,16,36]$. Antioxidant activity counters platelet oxidation and platelet dysfunction and therefore preserves platelets lifespan and increases their overall count [36]. Hence it has been reported that total flavonoid content in the methanolic leaves extract of S. cumini were highest than other commonly utilized parts, seeds and pulp [16].

According to pharmacochemist's opinion, isolation of active compound(s) from methanolic extract of $S$. cumini should be carried out to identify newer anticoagulant prototypes. Moreover, thorough pharmacological studies should then be further conducted in order to determine their complete and molecular mechanism(s) of action. Also, to perform investigation of potential antithrombotic activity of isolated molecule(s) from S. cumini leaves.

However, extraction of plant material performed in this study was not exactly same as to the traditional approach when the interior Sindh population used water for extracts, whereas, we have used methanol due to greater pharmacological activity reported in previous studies. It was worthful to conduct in vivo studies on $S$. cumini extract and should determine adverse effects of the active constituents, pharmacokinetic properties, serum-attainable levels and diffusion in different body tissues.

\section{Conclusion}

Hence, in the light of presence findings of this investigation it is concluded that antithrombin activity of methanolic extract of S. cumini leaves may be supported by its anti-inflammatory and antioxidant activities. Thus, antiplatelet effects and antithrombin activity of S. cumini leaves extract were found in our study. It opens a new window for future investigation on $S$. cumini leading to the development of an herbal therapeutic agent which may be of value in cardiovascular diseases.

\section{Protein C}

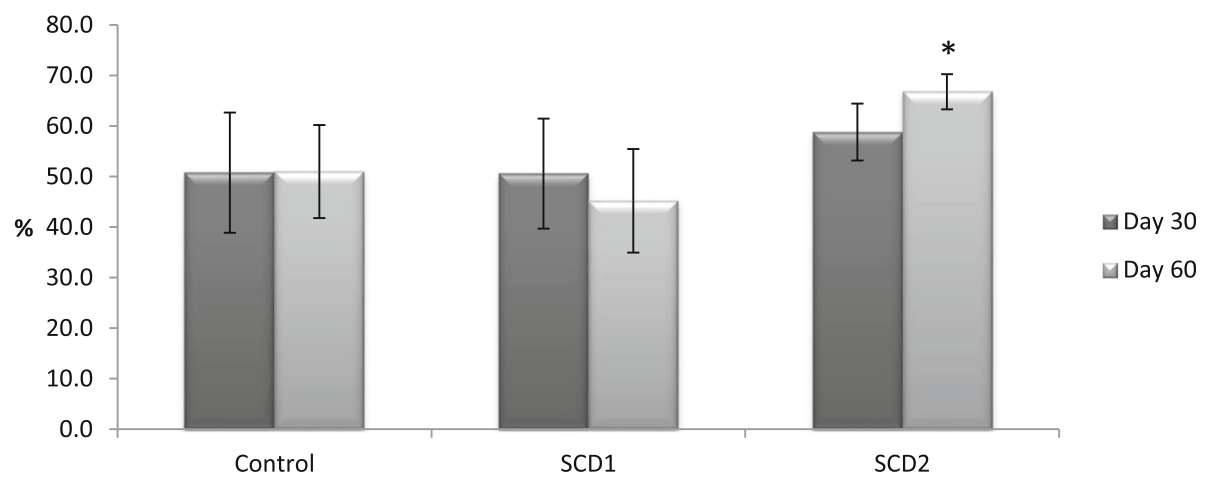

Fig. 1 Effects of Syzygium cumini and control on Protein C in rabbits. Data is represented as Average values \pm SEM, where $n=10$; Two different doses of S. cumini were used as follows: SCD1:150 mg/kg; SCD2: $500 \mathrm{mg} / \mathrm{kg},{ }^{*} p \leq 0.05$ significant as compared to control 


\section{TAT Complex}

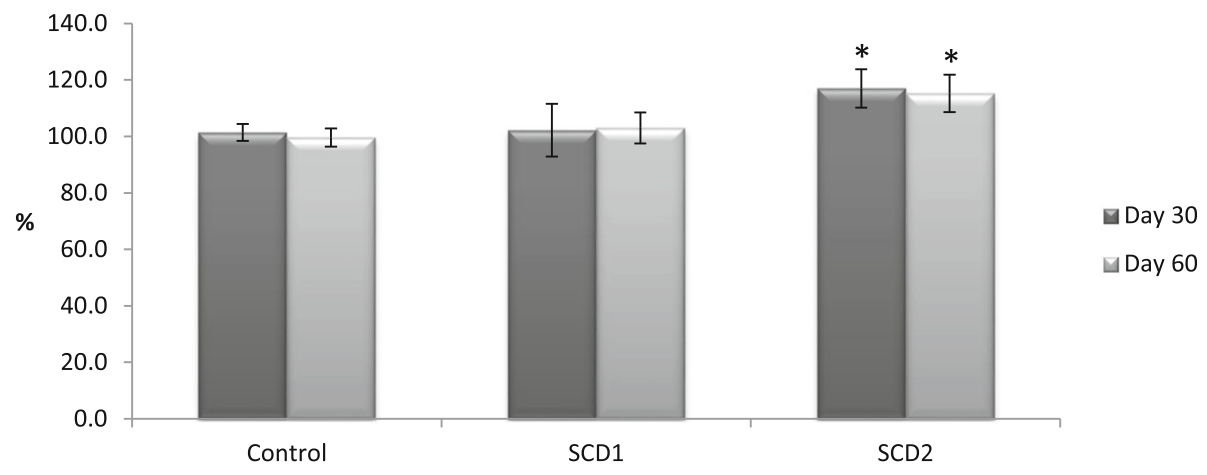

Fig. 2 In vivo effects of Syzygium cumini and control on TAT complex in rabbits. Data is represented as average values \pm SEM, where $n=10 ;$ Two different doses of S. cumini were used as follows: SCD1:150 mg/kg; SCD2: 500 mg/kg, ${ }^{*} p \leq 0.05$ significant as compared to control

\section{Abbreviations}

AA: Arachidonic acid; ADP: Adenosine diphosphate; aPTT: Activated partial thromboplastin time; AT-III: Anti-thrombin III; BT: Bleeding time; CAM: Complementary alternative medicines; DUHS: Dow university of health sciences; EDTA: Ethylene diamine tetra acetate; Fb: Fibrinogen; Hb: Hemoglobin; HCT: Hematocrit; MCH: Mean corpuscular hemoglobin; MCHC: Mean corpuscular hemoglobin concentration; MCV: Mean corpuscular volume; PC: Protein C; PPP: Platelets poor plasma; PRP: Platelets rich plasma; PT: Prothrombin time; RBCs: Red blood cells; SCD1: Syzygium cumini dose 1; SCD2: Syzygium cumini dose 2; SEM: Standard error mean; SPSS: Statistical package for social sciences; TAT: Thrombin antithrombin; TT: Thrombin time; WBCs: White blood cells; WHO: World health organization

\section{Acknowledgements}

This research work was not supported by any foundation or organization.

\section{Authors' contributions}

AAR conducted the whole study under AR supervision. MAA revised the paper and help during the practical work, SA, MLR and KK were responsible for drafting and writing the final version of the manuscript. All authors performed data analysis in addition they read and approved the final manuscript.

\section{Funding}

The authors didn't receive financial support from any institution.

\section{Availability of data and materials}

The data sets used and/or analyzed during the current study available from the corresponding author on reasonable request.

\section{Ethics approval and consent to participate}

The study was approved by local research ethics committee of Board of Advance Studies and Research, University of Karachi, Pakistan. Additionally, the written consent form was also filled by the in-charge of the animal house (DUHS) to use animals for our study.

\section{Consent for publication}

Not applicable.

\section{Competing interests}

The authors declare that they have no competing interests.

\section{Author details}

'Department of Pharmacology, Faculty of Pharmacy, Jinnah Sindh Medical University, Rafiqui H.J Shaheed Road, Karachi 75510, Pakistan. ${ }^{2}$ Department of Pharmacology, Faculty of Pharmacy, University of Karachi, Karachi, Pakistan. ${ }^{3}$ Department of Pharmaceutics, Faculty of Pharmacy, Jinnah Sindh Medical University, Rafiqui H.J Shaheed Road, Karachi 75510, Pakistan. ${ }^{4}$ Department of
Clinical Sciences, Faculty of Medicine, Lund University Hospital, Lund, Sweden.

Received: 24 May 2019 Accepted: 28 August 2019

Published online: 03 September 2019

\section{References}

1. Burns MM. Alternative medicine: herbal preparations. Clin Ped Emer Med. 2000:1:186-90.

2. Atchibri AOA, Brou KD, Kouakou TH, Kouadio YJ, Gnakri D. Screening for antidiabetic activity and phytochemical constituents of common bean (Phaseolus vulgaris L.) seeds. J Medic Plant Res. 2010;4:1757-61.

3. Mukerjee PK, Wahil A. Integrated approaches towards drug development from Ayurveda and other Indian system of medicine. J Ethnopharmacol. 2006:103:25-35.

4. Yeh GY, Davis RB, Phillips RS. Use of complementary therapies in patients with cardiovascular disease. Am J Cardiol. 2006;98:673-80.

5. Adhyapak MS, Kachole MS. Investigation of adverse effects of interactions between herbal drugs and natural blood clotting mechanism. J throm thrombol. 2016;41:644-7.

6. Mann KG, Butenas S, Brumme K. The dynamics of thrombin formation. Arterioscler Tromb Vasc Biol. 2003:23:17-25.

7. Wang X, Hsu MY, Steinbacher TE, Monticello TM, Schumacher WA. Quantification of platelet composition in experimental venous thrombosis by real-time polymerase chain reaction. Thromb Res. 2007;119:593-600.

8. Bandiola TMB, Corpuz MJAT. Platelet and leukocyte increasing effects of Syzygium Cumini (L.) skeels (Myrtaceae) leaves in a murine model. Pharm Anal Acta. 2018:9:1-6.

9. Ruan ZP, Zhang LL, Lin YM. Evaluation of the antioxidant activity of Syzygium cumini leaves. Molec. 2008;13:2545-56.

10. Avila-Peña D, Peña N, Quintero L, Suárez-Roca H. Antinociceptive activity of Syzygium jambos leaves extract on rats. J Ethnopharmacol. 2007;112:380-5.

11. Jain A, Sharma S, Goyal M, Dubey S, Jain S, Sahu J, Kaushik A. Antiinflammatory activity of Syzygium cumini leaves. Intern J Phytomed. 2010:2:124-6.

12. Schoenfelder T, Warmlin CZ, Manfredini MS, Pavei LL, Réus JV, Tristão TC, Costa-Campos L. Hypoglycemic and hypolipidemic effect of leaves from Syzygium cumini (L.) Skeels, Myrtaceae in diabetic rats. Rev Bras de Farmacog. 2010;20:222-7.

13. Chagas VT, França LM, Malik S, Paes AMDA. Syzygium cumini (L.) skeels: a prominent source of bioactive molecules against cardiometabolic diseases. Front Pharmacol. 2015;6:259.

14. Atale N, Chakraborty M, Mohanty S, Bhattacharya S, Nigam D, Sharma M, Rani V. Cardioprotective role of Syzygium cumini against glucoseinduced oxidative stress in $\mathrm{H} 9 \mathrm{C} 2$ cardiac myocytes. Cardiovasc Toxicol. 2013:13:278-89.

15. Pekkarinen SS, Heinonen IM, Hopia Al. Flavonoids quercetin, myricetin, kaemferol and (+)-catechin as antioxidants in methyl linoleate. J Sci Food Agri. 1999;79:499-506 
16. Mohamed AA, Ali SI, El-Baz FK. Antioxidant and antibacterial activities of crude extracts and essential oils of Syzygium cumini leaves. PLoS One. 2013; 8:e60269.

17. Jasprica I, Mornar A, Debeljak Ž, Smolčić-Bubalo A, Medić-Šarić M, Mayer L, Šverko V. In vivo study of propolis supplementation effects on antioxidative status and red blood cells. J Ethnopharmacol. 2007;110:548-54.

18. Riaz A, Khan RA. Anticoagulant, antiplatelet and antianemic effects of Punica granatum (pomegranate) juice in rabbits. Blood Coagul Fibrinolysis. 2016;27:287-93.

19. Zakaria ZA, Sani MHM, Cheema MS, Kader AA, Kek TL, Salleh MZ. Antinociceptive activity of methanolic extract of Muntingia calabura leaves: further elucidation of the possible mechanisms. BMC Complement Altern Med. 2014;14:63.

20. Li H, Cone J, Fong M, Kambayashi J, Yoshitake M, Liu Y. Antiplatelet and antithrombotic activity of cilostazol is potentiated by dipyridamole in rabbits and dissociated from bleeding time prolongation. Cardiovasc Drugs Ther. 2005;19:41-8.

21. McNerlan SE, Crawford VL, Stout RW. Measurement of fibrinogen in frozen plasma. Thromb Res. 1997:88:481-4.

22. Son DJ, Lee HW, Shin HW, Lee JJ, Yoo HS, Kim TJ, Yun YP, Hong JT. Enhanced release of sphingosine-1-phosphate from hypercholesterolemic platelets: role in development of hypercholesterolemic atherosclerosis. Prostaglandins Leukot Essent Fatty Acids. 2008;78:383-90.

23. Jeong YH, Hwang JY, Kim IS, Park Y, Hwang SJ, Lee SW, et al. Adding cilostazol to dual antiplatelet therapy achieves greater platelet inhibition than high maintenance dose clopidogrel in patients with acute myocardial infarction: results of the adjunctive cilostazol versus high maintenance dose clopidogrel in patients with AMI (ACCEL-AMI) study. Circ Cardiovasc Interv. 2010;3:17-26.

24. Wayne PA. "collection, transport and processing of blood specimens for coagulation testing and general performance of coagulation assays," approved guideline H21-A2, 3rd edition, National Committee for Clinical Laboratory Standards; 1998.

25. Mumtaz N, Naqvi SBS, Asghar MA, Asghar MA. Assessment of antimicrobial activity of Sphaeranthus indicus L. against highly resistant pathogens and its comparison with three different antibiotics. J Dis Glob Health. 2017:10:67-73.

26. Gentry PA. Comparative aspects of blood coagulation. Veter J. 2004;168: 238-51.

27. Rao LV, Okorodudu AO, Petersen JR, Elghetany MT. Stability of prothrombin time and activated partial thromboplastin time tests under different storage conditions. Clin Chim Acta. 2000;300:13-21.

28. Mitropoulos KA, Esnouf MP, Meade TW. Increased factor VII coagulant activity in the rabbit following diet-induced hypercholesterolaemia: evidence for increased conversion of VII to aVIla a and higher flux within the coagulation pathway. Atherosclerosis. 1987;63:43-52

29. Miller GJ. Dietary fatty acids and the haemostatic system. Atherosclerosis. 2005;179:213-27

30. Cao P, Xie P, Wang X, Wang J, Wei J, Kang WY. Chemical constituents and coagulation activity of Agastache rugosa. BMC Complem Altern Med. 2017:17:1-8.

31. Riaz A, Khan RA, Mirza T, Mustansir T, Ahmed M. In vitro/in vivo effect of Citrus limon. (L. Burm. F.) juice on blood parameters, coagulation and anticoagulation factors in rabbits. Pak J Pharm Sci. 2014;27:907-15.

32. Chandler $\mathrm{WL}$, Velan $\mathrm{T}$. Estimating the rate of thrombin and fibrin generation in vivo during cardiopulmonary bypass. Blood. 2003;101:4355-62.

33. Lipe B, Ornstein DL. Deficiencies of natural anticoagulants, protein C, protein S, and antithrombin. Circulation. 2011;124:365-8.

34. Oyedemi SO, Adewusi EA, Aiyegoro OA, Akinpelu DA. Antidiabetic and haematological effect of aqueous extract of stem bark of Afzelia africana (smith) on streptozotocin-induced diabetic Wistar rats. Asin Paci J Trop Biomed. 2011:1:353-8.

35. Mahmoodi M, Hajizadeh M, Rashidinejad H, Asadikaram G, Khaksari M, Mirzaee $\mathrm{M}$, et al. Survey of changes in complete blood count and red cell indices of whole blood incubated in vitro at different temperatures up to 48 hours. J Ayub Med Col Abbott. 2008;18:1-3.

36. Li W, Xie R, Fan Z, Yang J, Liang W, Wu Q, et al. The contribution of oxidative stress to platelet senescence during storage. Transfusion. 2019; 59(7):2389-402 In Press.

\section{Publisher's Note}

Springer Nature remains neutral with regard to jurisdictional claims in published maps and institutional affiliations.

Ready to submit your research? Choose BMC and benefit from:

- fast, convenient online submission

- thorough peer review by experienced researchers in your field

- rapid publication on acceptance

- support for research data, including large and complex data types

- gold Open Access which fosters wider collaboration and increased citations

- maximum visibility for your research: over $100 \mathrm{M}$ website views per year

At $\mathrm{BMC}$, research is always in progress.

Learn more biomedcentral.com/submissions 